\section{Ontario Research Foundation}

Is his annual report for 1947 to the chairman and governors of Ontario Research Foundation (43 Queens Park, Toronto 5), the Director of Research refers to the virtual completion of the extension of the main building and to a considerable expansion of the scientific and administrative staff. During the year a new Industrial Research Services Department was established particularly to help the numerous small industrial units of the Province, and the Department is expected to handle about two thousand inquiries a year. The Chemistry Department prepared a com. prehensive report for the Minister of Mines on the processes in operation for the removal of sulphur gases from smelter fumes; fellowships were concerned with emulsion inks, waxes and transparent paper, sulphite liquor, the manufacture of carboxymethylcellulose, and the polymerization systems butadienestyrene, butadiene - isoprene and isoprene-styrene. In the Department of Engineering and Metallurgy, sixty-seven investigations were undertaken on behalf of various firms, and fellowships on the influence of chemical composition and physical structure of forged steel balls and their resistance to wear during grinding, and on wire rope, and work on the economics of ferrous smelting in Ontario continued. The Department of Parasitology carried further its work on the life-histories and the factors influencing the activity of black flies and leucocytozoon infection in ruffed grouse and other birds, especially domestic ducklings. Several drugs used successfully in combating malarial infection in man gave negative results on infected birds.

The Physiography Department is completing a study of the geological history of southern Ontario, has co-operated with the Department of Agriculture in a chemical investigation of pasture grasses, and has assisted the Meteorological Service of Canada in equipping and supervising twelve new weather stations at selected points. The work of the Textiles Department has been handicapped by shortage of staff and accommodation ; but the Courtaulds (Canada) Ltd. fellowship has continued its work on dye formulæ and methods of finishing and the development of consumer standards, while under the Canadian Industries Ltd. fellowship, in addition to developing fabric construction to meet the demands of the consumer, the behaviour of the nylon fibre under different physical and chemical conditions is being investigated. Some progress is also reported by the Department in investigations on the transmission of water vapour through fabrics, the physical properties of nylon and the factors involved in removing oils used as lubricants after processing textile materials.

\section{Barton's Ruling Engine}

Is the possession of the Science Museum, London, there are six beautifully engraved buttons, classified as diffraction gratings, which are still regarded as masterpieces. They were the work of Sir John Barton, deputy comptroller of the Royal Mint in the early part of the nineteenth century, about whom little is known personally, but who must have been an ingenious inventor and capable engineer, for in 1806 he invented a differential screw measuring instrument capable of measuring to $10^{-5}$ inch. In 1822 he was granted a patent for his engraved buttons. After Sir John's death the ruling engine on which the buttons had been ruled passed into the possession of his grandson and then to his greatgrandson, Mr. R. V. Barton, who, in 1925, presented the engine, together with some handwritten notes of his father's concerning the working of the machine, to the Science Museum. The above details are given in a valuable and interesting illustrated article entitled "A Ruling Engine Used by Sir John Barton-and its Products" which P. Grodzinski, the technical editor of the Industrial Diamond Review, contributes to the February number of that journal. It would appear that this is the first authoritative description.

From his inspection of the machine and relevent documents, Grodzinski concludes that the engine was not Barton's own design but is probably a Harrison straight-line engine. The machine itself is made of brass except for the screws, spindles and pivots, which are steel. The tools are of well-ground steel; but diamond tools, generally octahedral Brazilian stones with curved edges, are provided. Six engraving tools work on six specimens simultaneously, and the method of movement of the tools is ingenious, kinematically sound, and simple. It is fully described in the article, with clear diagrams and photographs. The high precision of division and the engraving of six specimens at once are the special merits of this machine.

Tables of Uranus for the Period 4000 B.C.-A.D. 3000

MM. M. Kamieński and R. Walter have a paper with this title (Extrait Bull. de l'Acad. Polon. Sci. et Lettres, 1947) which provides a simple and rapid method for finding the heliocentric co-ordinates of Uranus, the perturbations of the other planets having been taken into consideration in the compilation of the Tables. An explanation of the method for applying the 'Tables is given, and an accuracy of about $\mathbf{1}^{\prime}$ is obtainable, which is sufficient in a great many cases. The Tables should prove very useful, especially in investigating the influence of Uranus on the motions of comets in ancient times, though, of course, they will prove helpful in many other cases as well. Special investigations were made of the long-period inequalities of Uranus, and it seems that these, namely, those of the mean longitude, the eccentric angle, longitude of perihelion, and semi-major axis, can be approximately represented by a Fourier interpolation formula. These inequalities are so regular that the corresponding formula for perturbations in longitude can be extended even beyond the limits of the Table, for the period 6500 B.C.-A.D. 5500, with a mean error of less than $1^{\prime}$.

\section{Conference on Experimental Biology, Peiping}

MoRe than one hundred teachers, research workers and senior students in biology of the universities and institutions of Peiping met in the new campus of the College of Agriculture of the National Tsinghua University during July 17-25. The instigator of the conference was Dean P. S. Tang, ably and generously assisted by his colleagues of the College. The campus is next to the famous Summer Palace which was freely accessible to the members during this conference, and one of the most enjoyable parts was the boating at night on the lake inside the Palace. Preliminary meetings consisted of lectures on the place of biology in ancient Chinese history, and on the teaching methods of biology in colleges and high schools. So many contributed valuable suggestions to the latter subject that a special committee was appointed to explore further this important and fertile field. The regular programme consisted of symposia and lectures on recent advances in genetics, hormones, nutrition, viruses and rickettsia, 
biophysics and aviation physiology. The round-table meetings were attended chiefly by senior members, and the following topics were discussed : cytology, growth and development, immunity, and effect of temperature on organisms. The general impression of the conference was that the time allotted to each speaker was too short, and plans are being made to choose one or two important subjects as the theme of the conference next summer. It was fortunate that the Peiping branch of the Chinese Society of Phytopathology was able to meet with the conference on the afternoons of July 20 and 21.

\section{Hallucinations}

THe Proceedings of the Society for Psychical Research for July (48, Pt. 175) has a suggestive and highly critical article by the research officer, Dr. D. J. West, in which he examines afresh the evidence hitherto collected by the Society for the supernormality of such spontaneous phenomena as precognitive dreams, apparitions and other forms of hallucinations. In the case of the precognitive dream Dr. West concludes that a perfect case has not yet been printed in the Society's publications. "There is always a flaw somewhere," he writes, adding that "the perfect case is a myth" (p. 271). In dealing with the crisis apparition, he points out that numerous and unsuspected sources of error abound, and he indicates his dissatisfaction with the evidence on which those condueting the famous Census of Hallucinations were inclined to rely. Finally, he points out how better evidence could be secured if witnesses could be persuaded to forward their results immediately to some independent source, so that adequate inquiries might be forthwith made and the original documents preserved for subsequent examination and verification.

\section{New Fungi of Madras}

A NEW species of discomycete fungus, Bulgariastrum tumifaciens, which causes galls upon living leaves and inflorescences of Capparidis sepiarioe is described by T. S. and K. Ramakrishnan (Proc. Ind. Acad. Sci., 27, B, 2; Feb., 1948). This is one of seven new species named by the same authors in their most recent additions to the purely indigenous fungus flora of Madras.

\section{Culture Collections of Micro-organisms}

As a result of a recommendation of the Specialist Conference of Culture Collections of Micro-organisms held in London in August 1947 under the auspices of the Standing Committee of the British Common. wealth Scientific Official Conference (1946), national committees were established in the several Dominions and in the United Kingdom for the co-ordination of the activities of existing collections of micro-organisms and to assist in the preparation of collection catalogues. The United Kingdom National Committee will deal also with the Crown Colonies. As a first step in this work, national committees are circulating a. questionnaire to all laboratories in their areas at which collections of micro-organisms are known or believed to be maintained. Inevitably some such collections will be missed, particularly those in private hands. Owners of collections of microorganisms in the United Kingdom and Crown Colonies who have not received a questionnaire are asked to notify Dr. Martin Ware, secretary of the United Kingdom National Committee, at the Medical Research Council, 38 old Queen Street, Westminster, London, S.W.1.

\section{Installing of Electric Discharge Lamps}

DEVELOPMENTS in electric discharge lamps and the very rapid increase in their application have produced an urgent requirement for the revision of Section 8 of the Regulations for the Electrical Equipment of Buildings issued by the Institution of Electrical Engineers. A new edition, the twelfth, of the Regulations is at present in preparation; but to meet this immediate need Revised Section 8, "The Installing of Electric Discharge Lamps", has been produced and supersedes, as from July 1, the corresponding section of the eleventh edition. Fluorescent tubes operating at normal mains voltage become, for the first time, a subject of specific requirements under Section $8 A$, which covers all discharge lamp installations in which the open-circuit voltage does not exceed 650 volts. Section $8 B$ gives additional requirements for high-voltage installations up to 5,000 volts to earth, which is the maximum voltage permissible.

\section{Colonial Services Appointments}

THE following appointments in the Colonial Services have been announced: E. S. Porter, agricultural officer, Kenya ; H. C. Butcher, chemist, Federation of Malaya; A. R. Giles, land surveyor, Hong Kong ; A. L. Griffith, temporary forest officer, Zanzibar ; R. A. Neve, specialist, Agricultural Department, Gold Coast; A. G. A. Sutton, Government geologist, Mines Department, Trinidad; R. H. Wharton, medical entomologist, Federation of Malaya; J. G. M. King (agricultural officer, Tanganyika), direct $\mathbf{r}$ of livestock and agricultural services, Basutoland; H. S. Purchase (senior veterinary research officer, Kenya), chief veterinary research officer, Kenya.

\section{Royal Society Scientific Information Conference}

A suMmary of the recommendations of the Scientific Information Conference held during June 21-July 2 has now been issued to delegates; they will be included in the report of the Conference which is now in preparation. The Council of the Royal Society considered these recommendations on July 8, and agreed to receive them. In one of the recommendations the Conference invited the Royal Society to consider setting up a standing committee on scientific information services, and the Council has agreed in prineiple to do this.

\section{Announcements}

A ReFresher COURSE on "The Mechanical Working of Metals" is being organised by the Institution of Metallurgists and will be held at Ashorne Hill, Leamington Spa, during the week-end beginning October 1. Among those giving lectures are Dr. Hugh Ford, Dr. R. Genders, Dr. E. Orowan, Dr. L. B. Pfeil, Prof. H. W. Swift and Prof. F. C. Thompson.

A Fine Chemical Group of the Society of Chemical Industry, for "the discussion of fine chemicals, especially those of therapeutic or biological interest", has been formed. Meetings are to be held monthly, and the opening address will be delivered by Prof. J. H. Burn, on "Fine Chemicals for Medical Use", at the Royal Institution, London, W.1, on October 5. The chairman of the Group is Sir Jack Drummond, and the honorary secretary is Dr. W. Mitchell, Messrs. Stafford Allen and Sons, Ltd., Wharf Road, London, N.1. 